\title{
THE RISK OF HYDROGEN EXPLOSION IN A SUBMARINE PART 3 PRODUCTION OF HYDROGEN MIXES
}

\section{Ryszard Kłos}

Polish Naval Academy, Department of Underwater Work Technology in Gdynia, Poland

\section{ABSTRACT}

This series of articles presents the problems associated with the conduction of a high-risk project aimed at modernising the hydrogen combustion engines on a submarine. The article describes technical issues connected with obtaining hydrogen-air mixes.

Keywords: hydrogen-air mixes, oxyhydrogen, production of gas mixes, stream mixing method

\section{ARTICLE INFO}

PolHypRes 2017 Vol. 57 Issue 1 pp. 7 - 24

ISSN: $1734-7009$ elSSN: 2084-0535

DOI: $10.1515 /$ phr-2017-0028

Pages: 18 , figures: 10 , tables: 7

page www of the periodical: www.phr.net.pl

Publisher

Polish Hyperbaric Medicine and Technology Society

\section{Original article}

Submission date: 02.07.2017r.

Acceptance for print: 15.12.2016r. 


\section{INTRODUCTION}

The process of obtaining the correct hydrogenair mixes constitutes the key element of research on catalytic hydrogen oxidation. It was assumed that during testing, the possibility of fuelling the incinerator with properly composed hydrogen and air mixes would be ensured.

In the discussed case it was necessary to guarantee the air flow of $\dot{V}_{0} \in[0 ; 150] \mathrm{m}^{3} \cdot h^{-1} \triangleq$ $[0 ; 2500] \mathrm{dm}^{3} \cdot \mathrm{min}^{-1}$ and hydrogen flow of $\dot{V}_{\mathrm{H}_{2}} \in$ $[0 ; 4.5] \mathrm{m}^{3} \cdot \mathrm{h}^{-1} \triangleq[0 ; 75] \mathrm{dm}^{3} \cdot \mathrm{min}^{-1}$.

This means that the maximum volumetric concentration of hydrogen $x_{H_{2}}^{\max }$ should amount to $x_{\mathrm{H}_{2}}^{\max }=\frac{4.5}{150}=0.03 \mathrm{~m}^{3} \cdot \mathrm{m}^{-3}$ and fall approximately at $0.01 \mathrm{~m}^{3} \cdot \mathrm{m}^{-3}$ below the generally adopted lower explosive limit.

\section{HYDROGEN EXPLOSIVE LIMITS}

The commonly adopted lower explosive limit for hydrogen in the air $L E L^{1}$, for a dry mixture in normal conditions is equal to $L E L=(4.1 \pm 0.1) \%_{v} H_{2} /$ air whereas the upper explosive limit $U E L$ is set at approximately $U E L \cong 75 \%{ }_{v} \mathrm{H}_{2} / \mathrm{air}^{2}$. The defined explosive limits concern ignition triggering by an electric spark. It is assumed that heating of a hydrogen-air mixture to the temperature of $t=350^{\circ} \mathrm{C}$ is safe and the limit value is the temperature $t=585^{\circ} \mathrm{C}[1,2]-$ fig. 1 . Between these values

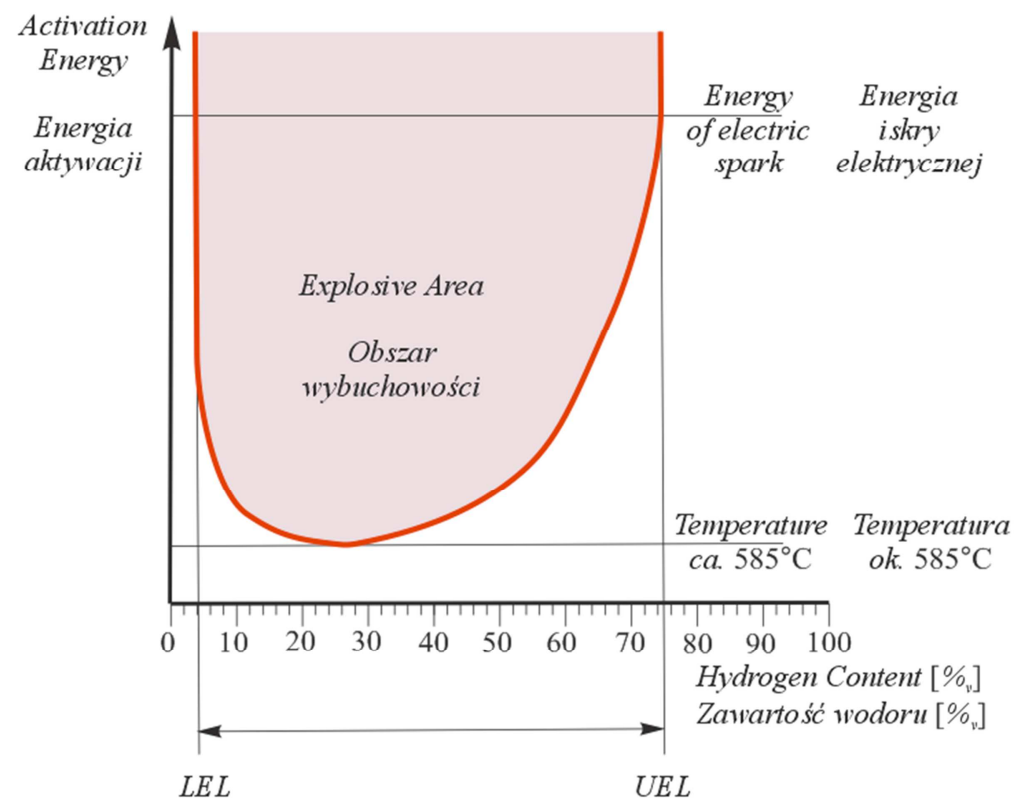

Fig. 1. Schematic diagram illustrating the process of defining the lower $L E L$ and upper $U E L$ explosive limits for a hydrogen-air mix [1,3].

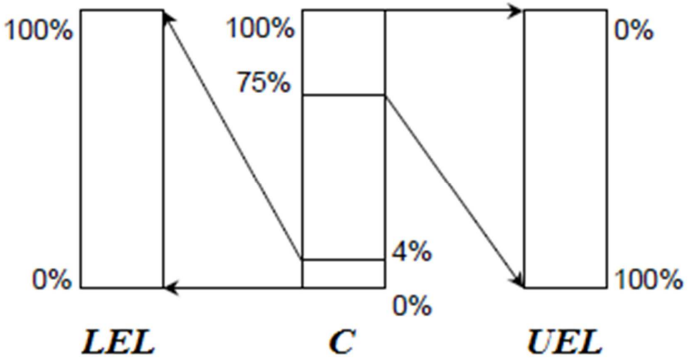

Fig. 2. The commonly adopted values of lower $D G W$ and upper $G G W$ explosive limits for a hydrogen-air mix at a normal pressure $p_{0}=101.325 \mathrm{kPa}$ and temperature $t=20^{\circ} \mathrm{C}[1,4]$ 


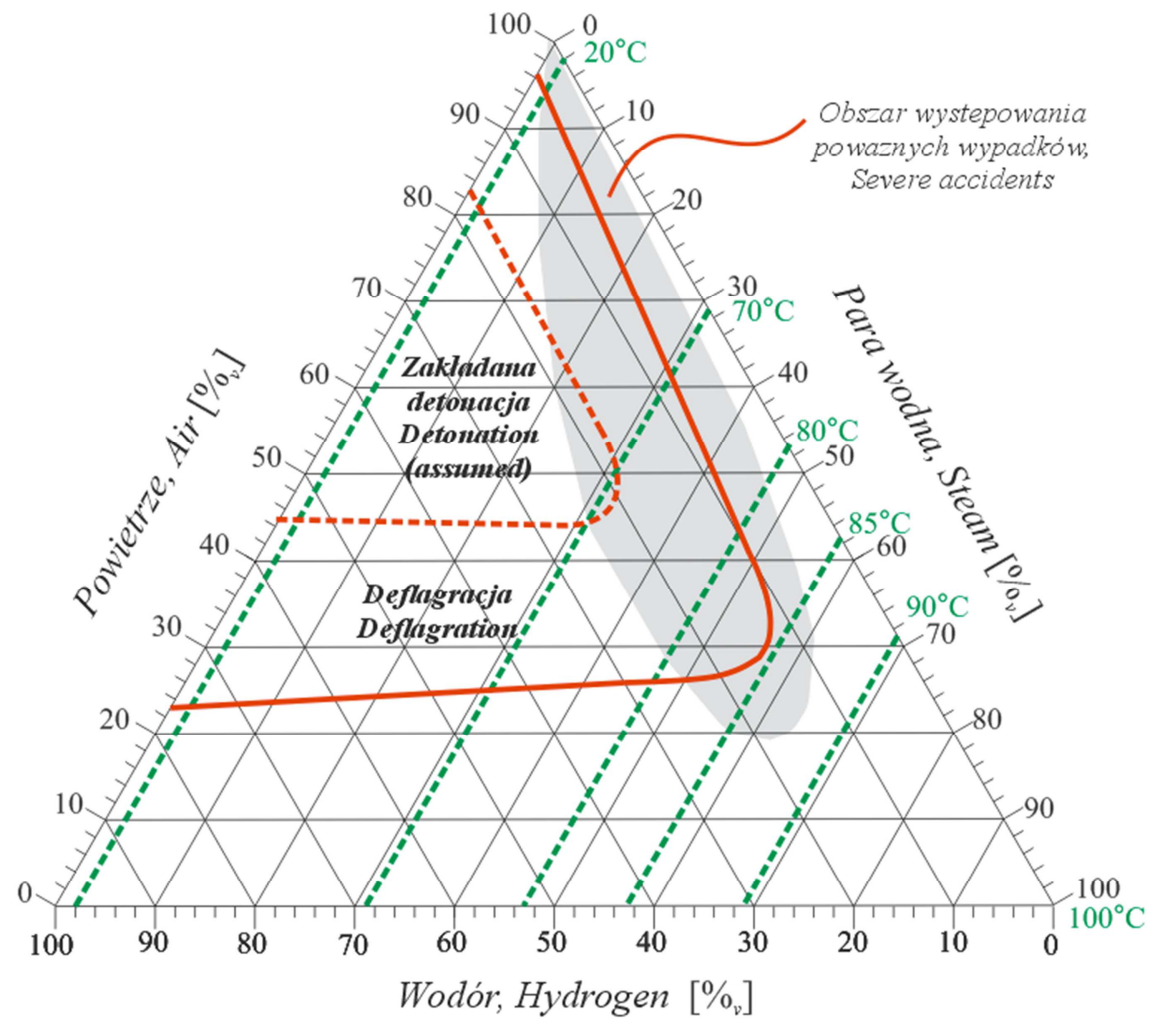

Fig. 3. The explosive limits for a hydrogen-air-steam mix at a normal pressure and relative humidity referred to the temperature of saturated steam [2,5].

is what we refer to as the explosive range ${ }^{3} E R{ }^{4}$. It is often expressed in the accepted explosiveness scales. The mutual dependences of the explosive range $E R$, dangerous concentrations $C$ and accepted explosive limits for a hydrogen-air mix air mix are presented in fig. 2 .

\section{RECOMMENDATIONS}

The limits ${ }^{5}$ presented in fig. 3, with regard to deflagration phenomenon ${ }^{6}$, have been defined on the basis of experiments, whereas those for detonation 7 are a result of theoretical considerations. According to fig. 3 the explosiveness of a hydrogen-air mix is largely affected by the humidity content -[6,7]. For instance, rapid combustion of a steam-saturated hydrogen-air mix in atmospheric pressure and at a temperature above $t>85^{\circ} \mathrm{C}$ does not occur irrespective of hydrogen content in the air. The determination of these unusual conditions is a result of research on safety levels of $P W R^{8}$ nuclear reactors.

In the studies on catalysts used in hydrogen combustion engines, an important conclusion is that steam provides additional protection against the possibility of an explosion. In order to increase safety, it is worth conducting trials in which the air sucked in through the intakes possesses a high humidity. During the tests, hydrogen concentration is expressed as a volumetric fraction $x_{v}$ and the value $x_{v}<x_{v}^{\max }=0.03 \mathrm{~m}^{3}$. $m^{-3} \mathrm{H}_{2}$ /air should never be exceeded.

\section{INTRODUCTION}

It was experimentally confirmed that after exceeding a certain limit in the pressure ratio between the inlet $p_{1}$ and outlet $p_{2}$ of the nozzle, despite pressure variation at the outlet ${ }^{9} p_{2}$, the stream of a mass $\dot{m}$ of a flowing gas mixture remains at a constant level $\dot{m}=i d e m$. In other words, variations in back pressure $\downarrow p_{2} \uparrow$ for pressure ratios at the inlet and outlet $\beta=\frac{p_{2}}{p_{1}}$ falling below the critical limit value $\beta<\beta_{k r}$, will not cause a change in the mass stream $\dot{m}=i d e m$ of the flowing gas mix.

This serves as the basis for the calculation of the capacity of nozzles operating in supercritical flows. A properly selected set, consisting of a pressure regulator and a dosing nozzle, ensures the supply of a constant stream of a gas mix mass $\dot{m}=i d e m$. By developing the required mathematical model we may obtain a differential form of Bernoulli's equation.

\section{BERNOULLI'S EQUATION}

Bernoulli's equation is derived from the principle of energy conservation. Assuming that there is not internal friction ${ }^{10}$ we may write down the differential energy balance per 1 mole of gas [6,7]:

$$
d e=d e_{k}+d e_{p}+d e_{o}+d e=q_{e l}-w_{e l}
$$

where: $e-$ total molar energy of the system; $e_{k}$-molar kinetic energy of the system; $e_{p}$-potential molar energy of the system; $e_{o}$-volumetric molar energy of the system; $u$-internal molar energy of the system; $q_{e l}$-molar energy exchanged as heat between the system and environment; $w_{e l}$-molar energy exchanged as work, with the exclusion of volumetric work, between the system and environment.

Equation (1) utilises the el symbol instead of the complete differential symbol to define small changes in molar energies exchanged as heat $q_{e l}$ and non-volumetric work $w_{e l}$. Such a procedure is dictated in order to distinguish state function ${ }^{11}$ from other partial functions which do not explicitly describe the system's state. Heat and work $^{12}$ do not usually constitute explicit state functions ${ }^{13}$. 
Particular energy parts occurring in balance (1) may be expressed as: $d e_{k}=d\left(\frac{v^{2}}{2}\right), d e_{p}=g \cdot d h$, $d u=d i-d(p \cdot v), \quad q_{e l}=d u+p \cdot d v, \quad d e_{o}=d(p \cdot v)$, where: $v$-gas flow velocity, $g$-gravity; $h$-height from the surface of the Earth, $i$-molar enthalpy; $p$-pressure; $\mathrm{u}$-molar volume. With the insertion of these equations into balance (1) and conducting proper transformations we receive the differential, molar form of the Bernoulli equation:

$$
d\left(\frac{v_{2}}{2}\right)+g \cdot d h+v \cdot d p=-w_{e l}
$$

\section{FLOW THROUGH THE NOZZLE}

For gas which does not perform volumetric work $w_{e l}=0$ and flows through horizontal pipe $d h=0$ from section 1 through the flange with aperture area $A_{0}$ into section 2, the Bernoulli equation (2) will take the following form - fig. 1.

$$
\int_{v_{0}}^{0} d\left(\frac{v^{2}}{2}\right)=-\int_{p_{1}}^{p_{2}} v \cdot d p \quad \rightarrow \quad \frac{v_{0}^{2}}{2}=\int_{p_{1}}^{p_{2}} v \cdot d p
$$

By use of a graphic interpretation of an integral illustrated in fig. 2, we may write the following:

\begin{tabular}{|c|c|c|c|}
\hline & $\begin{array}{l}1 \\
1 \\
1 \\
1 \\
1 \\
1\end{array}$ & 0 & $\begin{array}{l}1 \\
1 \\
1 \\
1 \\
1 \\
1 \\
1 \\
1\end{array}$ \\
\hline Cross Sections; przekroje & 1 & 0 & 2 \\
\hline Preassure; ciśnienie & $p_{1}$ & $p_{0}$ & $p_{2}$ \\
\hline Density; gestość & $\rho_{l}$ & & $\rho_{2}$ \\
\hline Speed; prędkość & & $v_{0}=f(\rho)$ & $v_{2} \cong 0$ \\
\hline Temperature; temperatura & $T_{1}$ & & $T_{2}$ \\
\hline Area; powierzchnia & & $A_{0}$ & \\
\hline
\end{tabular}

$$
\begin{aligned}
& \int_{p_{1}}^{p_{2}} v \cdot d p=\int_{v_{1}}^{v_{2}} p \cdot d v-\operatorname{Pole}\left(p_{2}, 2, \mathrm{v}_{2}, 0\right)+\operatorname{Pole}\left(p_{1}, 1, \mathrm{v}_{1}, 0\right) \\
& =\int_{\mathrm{v}_{1}}^{v_{2}} p \cdot d v-p_{2} \cdot \mathrm{v}_{2}+p_{1} \cdot \mathrm{v}_{1}
\end{aligned}
$$

Fig. 4. The conditions of a gas flow through a horizontal pipe with a flange of aperture area equal to $A_{0}$.

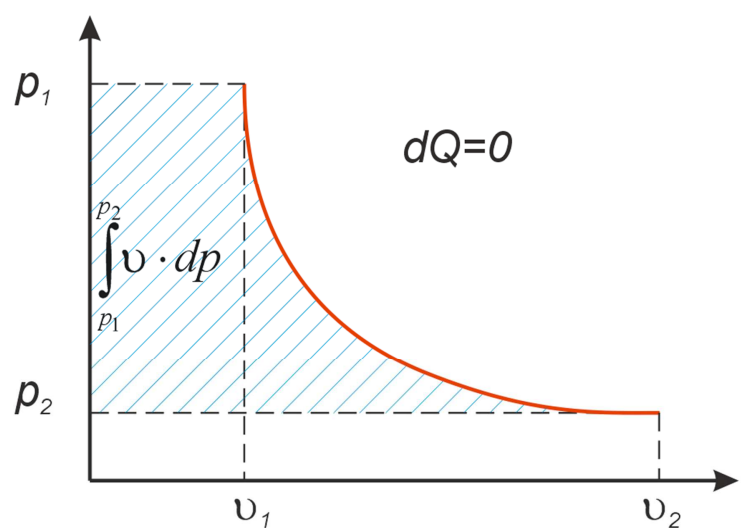

Fig. 5. Graphic interpretation of the integral $\int_{p_{1}}^{p_{2}} \mathrm{v} \cdot d p$ with coordinates $(p, v)$ for adiabatic transformation $d Q=0$.

Using the first law of thermodynamics ${ }^{14}$ for an isolated system we may write $p \cdot d v=c_{v} \cdot d T$, and, hence for the integral: $\int_{v_{1}}^{v_{2}} p \cdot d v=-\int_{T_{1}}^{T_{2}} c_{v} \cdot d T \equiv c_{v} \cdot\left(T_{1}-\right.$ $T_{2}$ ), where: $c_{v}$-molar thermal volume for isochoric transformation.

By marking molar thermal volume for isobaric transformation as $c_{p}$ and using the Clapeyron equation $p \cdot v=R \cdot T$ and general thermodynamic relationships for ideal gas $\frac{c_{p}}{c_{v}}=\kappa \wedge c_{p}-c_{v}=R$, we may write that $c_{p}-c_{v}=R=\frac{p_{1} \cdot v_{1}}{T_{1}}$, and thus: $c_{v}=\frac{p_{1} \cdot v_{1}}{(\kappa-1) \cdot T_{1}}$.

Next, by an insertion of the last equation into the integral $\int_{v_{1}}^{v_{2}} p \cdot d v=c_{v} \cdot\left(T_{1}-T_{2}\right) \quad$ we may write: $\int_{v_{1}}^{v_{2}} p \cdot d v=\frac{p_{1} \cdot v_{1}}{(\kappa-1) \cdot T_{1}} \cdot\left(T_{1}-T_{2}\right)$, and upon transformation receive: $\int_{v_{1}}^{v_{2}} p \cdot d v=\frac{p_{1} \cdot v_{1}}{(\kappa-1)} \cdot\left(1-\frac{T_{2}}{T_{1}}\right)$.

Using the Clayperon equation $p_{1} \cdot v_{1}=R$.

$T_{1}$ and Poisson formul $a^{15} p_{1} \cdot v_{1}{ }^{\kappa}=p_{2} \cdot v_{2}{ }^{\kappa}$ we may write:

$$
\frac{T_{2}}{T_{1}}=\frac{p_{2} \cdot v_{2}}{p_{1} \cdot v_{1}}=\frac{p_{2}}{p_{1}} \cdot\left(\frac{p_{1}}{p_{2}}\right)^{1 / \kappa}=\left(\frac{p_{2}}{p_{1}}\right)^{\kappa-1 / \kappa}
$$

If we insert this equation into an integral equation $\int_{v_{1}}^{v_{2}} p \cdot d v=\frac{p_{1} \cdot v_{1}}{(\kappa-1)} \cdot\left(1-\frac{T_{2}}{T_{1}}\right)$, we will obtain the following: 


$$
\int_{v_{1}}^{v_{2}} p \cdot d v=\frac{p_{1} \cdot v_{1}}{\kappa-1} \cdot\left[1-\left(\frac{p_{2}}{p_{1}}\right)^{\kappa-1 / \kappa}\right]
$$

By inserting the received equation (6) into equation (4), we will have:

$$
\int_{p_{1}}^{p_{2}} \mathrm{v} \cdot d p=p_{1} \cdot v_{1} \cdot \frac{1}{\kappa-1} \cdot\left[1-\left(\frac{p_{2}}{p_{1}}\right)^{\kappa-1 / \kappa}\right]+p_{1} \cdot \mathrm{v}_{1}-p_{2} \cdot \mathrm{v}_{2}
$$

Again, by the use of equation (5) $\frac{T_{2}}{T_{1}}=\frac{p_{2} \cdot v_{2}}{p_{1} \cdot v_{1}}=\frac{p_{2}}{p_{1}}$. $\left(\frac{p_{1}}{p_{2}}\right)^{1 / \kappa}=\left(\frac{p_{2}}{p_{1}}\right)^{\kappa-1 / \kappa} \quad$ we may write: $p_{2} \cdot v_{2}=p_{1} \cdot v_{1}$. $\left(\frac{p_{2}}{p_{1}}\right)^{\kappa-1 / \kappa}$. By an introduction of products $p_{1} \cdot v_{1}$ and $p_{2} \cdot v_{2}$ into the bracket, equation (7) can be transformed into the following form: $\int_{p_{1}}^{p_{2}} v \cdot d p=\frac{p_{1} \cdot v_{1}}{\kappa-1}$. $\left[1-\left(\frac{p_{2}}{p_{1}}\right)^{\kappa-1 / \kappa}+\kappa-1-\left(\frac{p_{2}}{p_{1}}\right)^{\kappa-1 / \kappa} \cdot(\kappa-1)\right]$. If we bring adiabatic index $\kappa$ before the bracket we may write: $\int_{p_{1}}^{p_{2}} v \cdot d p=p_{1} \cdot v_{1} \cdot \frac{\kappa}{\kappa-1} \cdot\left[-\frac{1}{\kappa} \cdot\left(\frac{p_{2}}{p_{1}}\right)^{\kappa-1 / \kappa}+1-\left(\frac{p_{2}}{p_{1}}\right)^{\kappa-1 / \kappa}+\right.$ $\left.\frac{1}{\kappa} \cdot\left(\frac{p_{2}}{p_{1}}\right)^{\kappa-1 / \kappa}\right]$. And upon cancellation we will receive ${ }^{16}$ :

$$
\int_{p_{1}}^{p_{2}} v \cdot d p=p_{1} \cdot v_{1} \cdot \frac{\kappa}{\kappa-1} \cdot\left[1-\left(\frac{p_{2}}{p_{1}}\right)^{\kappa-1 / \kappa}\right]
$$

By inserting equation (8) into (3): $\frac{v_{0}^{2}}{2}=\int_{p_{1}}^{p_{2}} v \cdot d p$ we can write: $\quad \frac{v_{0}^{2}}{2}=\int_{p_{1}}^{p_{2}} v \cdot d p=p_{1} \cdot v_{1} \cdot \frac{\kappa}{\kappa-1}$. $\left[1-\left(\frac{p_{2}}{p_{1}}\right)^{\kappa-1 / \kappa}\right]$. Thus, we can obtain a formula for gas outflow velocity $v_{0}$ through a flange with aperture area
$A_{0}$, as a function of initial gas state $\left(p_{1}, v_{1}\right)$ and pressure ratio $\beta=\frac{p_{2}}{p_{1}}$ :

$$
v_{0}=\sqrt{2 \cdot \frac{p_{1}}{\rho_{1}} \cdot \frac{\kappa}{\kappa-1} \cdot\left[1-\beta^{\kappa-1 / \kappa}\right]}
$$

where: $\rho_{1}$-initial molar density $\rho_{1}=\frac{1}{\nu_{1}} ; \beta$-pressure ratio $\beta=\frac{p_{2}}{p_{1}}$.

On the basis of the flow continu(it) law, we may write $\dot{m}=A_{0} \cdot v_{0} \cdot \rho_{0}$, whereas value $\rho_{0} \equiv \rho_{2}$ may be defined with the use of the Clayperon equation and equation (5). Upon transformations, we will obtain the following equation: $\rho_{2}=\rho_{1} \cdot \frac{p_{2} \cdot T_{2}}{p_{1} \cdot T_{1}}=\rho_{1} \cdot \beta \cdot \beta^{1-\kappa / \kappa}=\rho_{1}$. $\beta^{1 / \kappa}$. Hence, mass flow intensity $\dot{m}$ can be expressed as:

$$
\dot{m}=A_{0} \cdot \sqrt{p_{1} \cdot \rho_{1}} \cdot \sqrt{2 \cdot \frac{\kappa}{\kappa-1} \cdot\left[\beta^{2 / \kappa}-\beta^{\kappa+1 / \kappa}\right]}
$$

where: $\dot{m}$-mass flow

Equation (10) is known as the Saint-Venant-Wantzel euqation. If we introduce the so-called flow number $\Psi: \quad \Psi=\left[2 \cdot \frac{\kappa}{\kappa-1} \cdot\left(\beta^{2 / \kappa}-\right.\right.$ $\left.\left.\beta^{\kappa+1 / \kappa}\right)\right]^{0.5}=f(\beta ; \kappa)$, equation $(10)$ will then be expressed in an abbreviated form [11]:

$$
\dot{m}=A_{0} \cdot \Psi \cdot \sqrt{p_{1} \cdot \rho_{1}}
$$

where: $\Psi$-flow number.

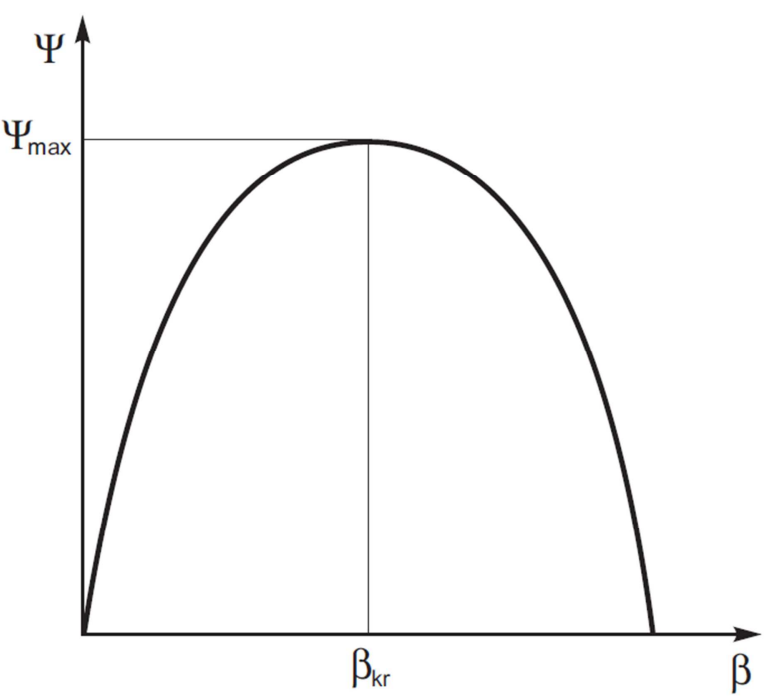

Fig. 6. Theoretical dependence of the flow number $\Psi$ in the function of pressure ratio $\beta$.

A graphic representation of the flow number $\Psi$ vs pressure ratio $\beta=p_{2} / p_{1}$ is a line with the maximum value for a certain critical value $\beta_{k r}-$ fig. 3 . The critical value for pressure ratio $\beta_{k r}$ can be found by calculating the derivative $\frac{\partial \Psi}{\partial \beta}$ and equating it to zero, hence:

$$
\forall \frac{\partial \Psi}{\partial \beta}=0 \quad \beta_{k r}=\frac{p_{2}}{p_{1}}=\left(\frac{2}{\kappa+1}\right)^{\kappa / \kappa-1}
$$

$\Psi_{\max }$ value can be found by inserting equation (12) into $\Psi=\left[2 \cdot \frac{\kappa}{\kappa-1} \cdot\left(\beta^{2 / \kappa}-\beta^{\kappa+1 / \kappa}\right)\right]^{0.5}$ :

$$
\Psi_{\text {max }}=\sqrt{\kappa \cdot\left(\frac{2}{\kappa+1}\right)^{\kappa+1 / \kappa-1}}
$$

The practical relationship between flow number $\Psi$ and pressure ratio $\beta=\frac{p_{2}}{p_{1}}$ will be slightly different from theoretical - fig. 4 . The values of constants $\kappa, \beta_{k r}, \Psi_{\max }$ and mean molar masses $\bar{M}$ of some gases are shown in tab. 1. 


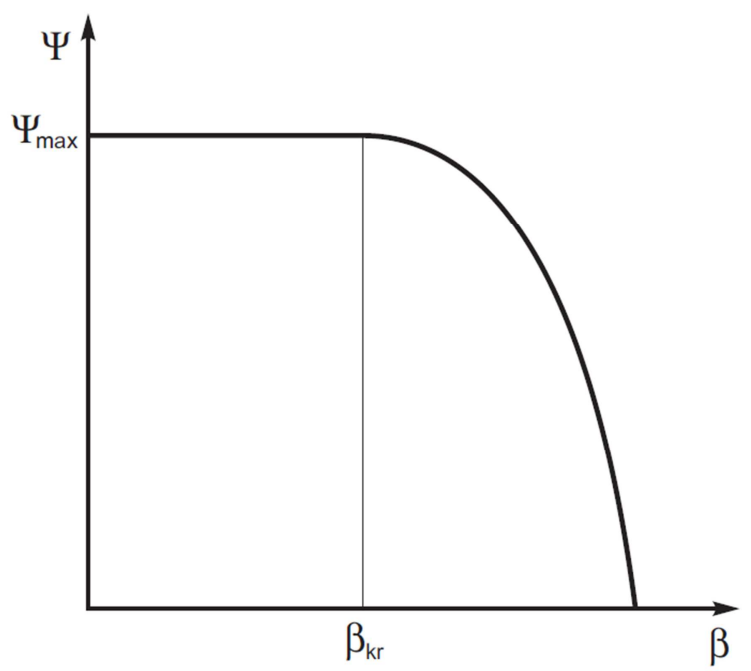

Fig. 7. Practical dependence of flow number $\Psi$ in the function of pressure ratio $\beta$.

\section{ROTAMETRIC MEASUREMENTS}

Flow intensity measurements are commonly performed with the use of rotameters. A schematic representation of a rotameter is shown in fig. 5. It consists of a glass tube widened towards the flow direction and the float. The float is maintained at a proper height depending on flow velocity. A gauge is placed on the tube, hence flow rate can be defined on the basis of the float's height. The following forces are exerted on the float suspended in the liquid:

The values of selected parameters for typical constituents of breathing mixes.

\begin{tabular}{|c|c|c|c|c|c|}
\hline & \multirow{2}{*}{$\kappa$} & \multirow{2}{*}{$\beta_{k r}$} & \multirow{2}{*}{$\Psi_{\max }$} & $\rho\left(p_{0} ; T_{0}\right)$ & $\bar{M}$ \\
\hline & & & & {$\left[\mathrm{g} \cdot \mathrm{dcm}^{-3}\right]$} & {$\left[\mathrm{g} \cdot \mathrm{mol}^{-1}\right]$} \\
\hline air & \multirow{4}{*}{1,4} & \multirow{4}{*}{0,528} & \multirow{4}{*}{0,685} & 1,293 & 28,96 \\
\hline tlen & & & & 1,429 & 31,999 \\
\hline oxygen & & & & 1,251 & 28,01 \\
\hline hydrogen & & & & 0,0899 & 2,016 \\
\hline
\end{tabular}

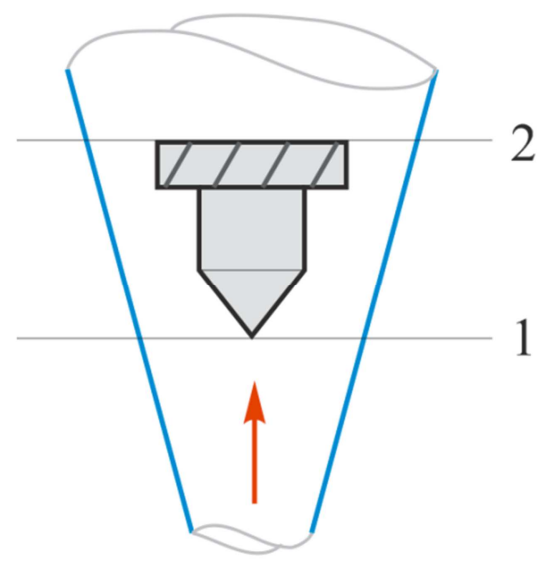

Fig. 8. Rotameter operation diagram.

$$
\begin{array}{lc}
\text { - gravitation } & \mathrm{G}=\mathrm{V}_{\mathrm{p}} \cdot \rho_{\mathrm{p}} \cdot \mathrm{g} \\
\text { - buoyancy } & W=V_{p} \cdot \rho \cdot g \\
\text { - force resulting from static } & P=\left(p_{1}-p_{2}\right) \cdot A_{2}
\end{array}
$$$$
\text { pressures remainder }
$$

where: $V_{p}$-rotameter float volume; $\rho_{p}$-rotameter float density; $\rho$-fluid density; $g$-gravitational acceleration; $p_{1}$-static pressure in section 1 fig. $5 ; p_{2}$-static pressure in section $2-$ fig. $5 ; A_{2}$-float cross-section in 2-2 plane - fig. 5
The float's balance is achieved when grativation force $G$ is balanced by buyonacy $W$ and the force resulting from static pressures difference $P$, hence, the said balance can be expressed as an equation: $G=W+P$. The balance of forces can be represented as follows:

$$
\left(p_{1}-p_{2}\right) \cdot A_{2}=V_{p} \cdot\left(\rho_{p}-\rho\right) \cdot g
$$

Balance (14) shows the levelling of static pressure difference $p_{1}-p_{2}$ generating hydrostatic force on the float through the float's weight $V_{p} \cdot\left(\rho_{p}-\rho\right) \cdot g$. 
If we ignore the low height of the float $h_{1} \cong h_{2}$ and density changes as a result of local pressure $\rho \cong i d e m$ we may formulate Bernoulli equation (2) for sections 1 and 2 demarcated in fig. 5: $p_{1}+\frac{v_{1}^{2}}{2} \cdot \rho=p_{2}+\frac{v_{2}^{2}}{2} \cdot \rho$, where: $v$-gas flow velocity for sections 1 and 2 from fig. 5 . Since free areas for the gas flow in the annular crosssection significantly differ $A_{2} \ll A_{1}$, it is required to assume that $v_{2} \gg v_{1}$, thus if we consider these relations, the equation $p_{1}+\frac{v_{1}^{2}}{2} \cdot \rho=p_{2}+\frac{v_{2}^{2}}{2} \cdot \rho$ can be simplified to an approximate form: $p_{1}-p_{2} \cong \frac{v_{2}^{2}}{2} \cdot \rho$.

By introducing this dependence into equation (14), we obtain: $v_{2} \cong\left(\frac{2 \cdot g \cdot V_{p} \cdot\left(\rho_{p}-\rho\right)}{A_{2} \cdot \rho}\right)^{0.5}$, hence the volumetric flow intensity $\dot{V}$ will be expressed by approximation as the following dependence: $\quad \dot{V} \cong A_{2} \cdot v_{2}=A_{2}$. $\left[\frac{2 \cdot g \cdot V p \cdot\left(\rho_{p}-\rho\right)}{A_{2} \cdot \rho}\right]^{0.5}$, where $v_{2}$ - gas stream flow velocity in section $A_{2}$. This equation constitutes an approximated relationship without taking into account, for example, the force resulting from the dynamic interaction with the float, or the friction on the float's surface. If we wish to consider this, it is necessary to introduce a correction factor $\alpha$ in the equation, referred to as the flow number:

$$
\dot{V} \cong \alpha \cdot A_{2} \cdot \sqrt{\frac{2 \cdot g \cdot V_{p} \cdot\left(\rho_{p}-\rho\right)}{A_{2} \cdot \rho}}
$$

where: $\alpha$-flow number; $A_{2}$ - section area free for a liquid flow at the height of the collar of the float fig. $5 ; g$-gravitational acceleration; $V_{p}$-float volume; $\rho_{p}$-float density; $\rho$-liquid density.

Flow intensity $\dot{V}$ is practically determined by the float's position in the rotameter tube. This may be illustrated by introducing into equation (15) an expression for the annular cross-section $A_{2}$, as the function of float's position $H$ :

$$
A_{2}=\frac{\pi}{4} \cdot\left(D_{0}+2 \cdot H \cdot \operatorname{tg} \frac{\varphi}{2}\right)^{2}-A=f(H)
$$

where: $D_{0}$ - the internal diameter of the conical rotameter tube in the section corresponding to the zero position on the scale; $\varphi$-opening angle of rotameter tube; $H$-float's position; $A$-cross-section area of the float's collar surface.

For the specified rotameter and unchangeable state of the measured mix, the expression under the square root sign in equation (15) has a fixed value of $\left[\frac{2 \cdot g \cdot V_{p} \cdot\left(\rho_{p}-\rho\right)}{A_{2} \cdot \rho}\right]^{0.5}=$ idem. This shows that the dependence of flow rate $\dot{V}$ on the float's height $H$ is not a linear function as it stems from equations (15) and (16).

Theoretically, the gauge on the rotameter tube also should not be even. In many cases, due to the small value $\operatorname{tg} \frac{\varphi}{2}$, and invariability of the flow correction number $\alpha \cong$ idem above limitary Reynolds numbers $R e>R e_{g r}$, it is possible to assume that the scale can be even with the exception of its beginning [11].

As a result of rotameter calibration, a characteristic is obtained specifying the relationship between volumetric flow intensity $\dot{V}$ and the float's position $H$. If we assume that the rotameter scale is linear, then the change in liquid parameters or an application of a different liquid in calibration, will result in a modification in the characteristic slant variation for the rotameter.

Calculation can be performed with the use of equation (15): $\dot{V} \cong \dot{V}^{\prime} \cdot \frac{\alpha}{\alpha^{\prime}} \sqrt{\frac{\left(\rho_{p}-\rho\right) \cdot \rho^{\prime}}{\left(\rho_{p}-\rho^{\prime}\right) \cdot \rho}}$, where symbols with the ' index refer to calibration conditions, and the symbols without indices to the conditions of measurements. In the case of gas rotameters, where float material density $\rho_{p}$ is many times higher than density of the gas measured $\rho: \rho_{p} \gg \rho$, the equation will be simplified to the following form: $\dot{V} \cong \dot{V}^{\prime} \sqrt{\rho^{\prime} \cdot \rho^{-1}}$. Practical application of this equation is difficult as usually the flow number $\alpha$ is not known. It stems from experience that the flow numbers quotient $\frac{\alpha}{\alpha^{\prime}}$ for collar floats is approximately equal to unity $\frac{\alpha}{\alpha^{\prime}} \cong 1$.

In the case of other float types, such a simplification is possible only when the viscosity of the calibration and measured liquid are similar, and the environmental parameters such as pressure and temperature at the time of measurement are only insignificantly different from their values during rotameter calibration. Should it be necessary to refer gas densities from under the square root sign to normal conditions, the simplified relation will take the following form:

$$
\dot{V} \cong \dot{V}^{\prime} \sqrt{\frac{p^{\prime} \cdot T}{p \cdot T^{\prime}} \cdot \frac{\rho_{0}^{\prime}}{\rho_{0}}} \mid \rho_{p} \gg \rho
$$

where: $\rho_{0}^{\prime}$-density in normal conditions of the gas medium for which the rotameter was scaled; $\rho_{0}$-density in normal conditions of the gas medium for which measurement was performed.

Often, for the purposes of comparison of volumetric flow measurement results, carried out in various temperature and pressure conditions, the measured flow is standardised to normal conditions:

$$
\dot{V}_{0}=\frac{T_{0} \cdot p}{T \cdot p_{0}} \cdot \dot{V}
$$

where: $\dot{V}_{0}$-volumetric flow intensity of the mix, measured in relation to normal conditions $T_{0}=273.15 \mathrm{~K} \wedge p_{0}=101.325 \mathrm{kPa} ; T_{0}$-temperature in normal conditions $\left[T_{0}=273.15 \mathrm{~K}\right] ; p_{0}$-normal pressure $\left[p_{0}=\right.$ $101.325 \mathrm{kPa}$ ]; $p$-atmospheric pressure at the time of measurement; $\dot{V}-$ mix flow intensity measured under measurement conditions

In order to calculate indications for mixes, first it is necessary to calculate density of the measured gas mix according to the relation: $\rho_{0}=\sum_{i} x_{v}(i) \cdot \rho_{0}(i)$, where: $\rho_{0}$ means gas mix density in normal conditions, $x_{v}(i)$ represents volumetric/molar fraction ${ }^{17} i$-of this gas component, whereas $\rho_{0}(i)$ density $i$-of this gas component in normal conditions. For ideal gases, the density of gas mixtures can be calculated with the use of the Clapeyron equation: $=\frac{p \cdot M}{R \cdot T}$, where $p$ stands for pressure, $M$ represents molar mass, $R$ universal gas constant, whereas $T$ - temperature. Hence, we may express it as:

$$
\dot{V}=\dot{V}^{\prime} \sqrt{\frac{p^{\prime} \cdot T}{p \cdot T^{\prime}}} \cdot \sqrt{\frac{M^{\prime}}{M}}=\dot{V}^{\prime} \sqrt{\frac{p^{\prime} \cdot T}{p \cdot T^{\prime}}} \cdot \sqrt{\frac{\rho_{0}^{\prime}}{\rho_{0}}}
$$

where: $\rho_{0}^{\prime}$-density of the liquid used in calibration in normal conditions: $\rho_{0}$-density of the measured liquid in normal conditions.

When comparing rotametric measurement results it is necessary to refer them to the same 
measurement conditions. Commonly they are standardised to normal conditions $-T_{0}=273.15 \mathrm{~K} \wedge$ $p_{0}=101.325 \mathrm{kPa}$. By the use of equation (18), equation (19) can be transformed into the following form:

$$
\dot{V}_{0}=\frac{T_{0} \cdot p}{T \cdot p_{0}} \cdot \dot{V}=\frac{T_{0} \cdot p}{T \cdot p_{0}} \cdot \sqrt{\frac{p^{\prime} \cdot T}{p \cdot T^{\prime}}} \cdot \sqrt{\frac{\rho_{0}^{\prime}}{\rho_{0}}} \cdot \dot{V}^{\prime}
$$

For a rotameter calibrated in normal conditions $p^{\prime} \equiv p_{0} \wedge T^{\prime} \equiv T_{0}$ relation (20) will assume the form:

$$
\dot{V}_{0}=\sqrt{\frac{p \cdot T_{0}}{p_{0} \cdot T}} \cdot \sqrt{\frac{\rho_{0}^{\prime}}{\rho_{0}}} \cdot \dot{V}^{\prime}
$$

Rotameters are usually designed to operate in a 1:10 ratio. Measurement accuracy ${ }^{18}$ is typically within $3 \%$. Rotameter's forming part of an installation must always be mounted in a vertical position. In principle, rotameters can be used to measure the flow rate in a pipe branch, which remains in a particular proportion to total flow. In the case of glass rotameters, the working pressure of liquids should not exceed $1 \mathrm{MPa}$.

It is common to use rotameters calibrated to the air in normal conditions.

In the case of a rotameter equipped with a collar float, calibrated to normal conditions with regard to the air flow, in approximation to the measurements conducted in normal conditions, for maximum assumed hydrogen flow at the level of $\dot{V}_{0}=75 \mathrm{dm}^{3} \cdot \mathrm{min}^{-1}$ a rotameter calibrated for the air should indicate: $\dot{V}($ pow. $) \cong 20 \mathrm{dm}^{3} \cdot \mathrm{min}^{-1}$

\section{DESIGN}

A continuous dosing system is composed of a nozzle working in supercritical flows - the correct operating conditions of which are ensured by the pressure regulator's reducing valve. Key design parameters of such a system will include: nozzle diameter $D$ and critical value of pressure reduced for hydrogen $p_{z}^{k r}\left(H_{2}\right)$.

\section{SUPPLY PRESSURE}

Using relation (12), it is possible to define the minimum supply pressure (hydrogen $p_{1}^{\text {min }}$ ) necessary for the nozzle to ensure supercritical flows of hydrogen are dosed through the nozzle into the air stream:

$p_{1}^{\min } \equiv p_{z}^{k r}\left(H_{2}\right)=\frac{p_{0}}{\beta_{k r}}=\frac{101,325 k P a}{0,528} \cong 0,2 \mathrm{MPa}$

where: $p_{z}^{k r}\left(H_{2}\right)$-minimal pressure supply value for the nozzle to ensure supercritical hydrogen flow; $\beta_{k r}$-critical pressure ratio $\beta=\frac{p_{2}}{p_{1}}$ for the nozzle fig. 1

\section{NOZZLE DIAMETER}

Due to the application of rotameter measurements, it is more convenient to replace mass flow $\dot{m}$ with volumetric flow $\dot{V}$ in relation (11): $\dot{V}=\frac{m}{\rho_{1}}=\Psi$. $A_{0} \cdot \sqrt{\frac{p_{1} \cdot \rho_{1}}{\rho_{1}^{2}}}=\Psi \cdot A_{0} \cdot \sqrt{\frac{p_{1}}{\rho_{1}}} \mid T=i d e m$,

where: $\dot{V}$-volumetric flow of the gas mix that is dosed relates to the measurement conditions; $\rho_{1}$-gas mix density before the nozzle; $A_{0}$-nozzle aperture area.

Using the Clapeyron equation $\rho_{1}=p_{1} \cdot \frac{\bar{M}}{R \cdot T}$ it is possible to transform the above relation into the following form: $\dot{V}=\Psi \cdot A_{0} \cdot \sqrt{\frac{R \cdot T}{\bar{M}}}=$ idem $\mid \beta<\beta_{k r} \wedge T=$ idem. By comparing the flow to normal conditions $p_{0}=101.325 \mathrm{kPa} \wedge t=0^{\circ} \mathrm{C}$, in concord with the Clapeyron equation, we may write:

$$
\dot{V}_{0}=\frac{p}{p_{0}} \cdot \frac{T_{0}}{T} \cdot \dot{V}=\frac{p}{p_{0}} \cdot \frac{T_{0}}{T} \cdot \dot{V} \cdot \Psi \cdot A_{0} \cdot \sqrt{\frac{R \cdot T}{\bar{M}}}
$$

where: $\dot{V}$-measured value of the dosed gas stream; $p$-atmospheric pressure at the time of measurement.

Function calculations $\left(\frac{\partial \dot{V}_{0}}{\partial p_{z}}\right)_{0^{\circ} \mathrm{C}}$ for particular pure gases and mixtures.

\begin{tabular}{llllllll}
\hline & & $\left(\frac{\partial \dot{V}_{0}}{\partial p_{z}}\right)_{0{ }^{\circ} \mathrm{C}}\left[\frac{d m^{3}}{M P a \cdot m i n}\right]$ & & & \\
\hline$D[\mathrm{~mm}] \rightarrow$ & 0,1 & 0,2 & 0,3 & 0,4 & 0,5 & 0,6 & Equation $\left(\frac{\partial \dot{V}_{0}}{\partial p_{z}}\right)_{0^{\circ} \mathrm{C}}$ \\
\hline hydrogen & 3 & 14 & 30 & 54 & 85 & 122 & $338,11 \cdot D^{2}$ \\
\hline
\end{tabular}

The slope of the straight line, constituting the curve of the dependence of the gas stream, refers to normal conditions in relation to reduced pressure $\dot{V}_{0}=f\left(p_{z}\right)$ is equal to the differential of stream $\dot{V}_{0}$, from relation (23), after supply pressure $p_{z}:\left(\frac{\partial \dot{V}_{0}}{\partial p_{z}}\right)_{\beta<\beta_{k r}}=\frac{T_{0}}{T}$. $\frac{\Psi_{\max }}{p_{0}} \cdot \sqrt{\frac{R \cdot T}{\bar{M}}} \cdot A_{0}$. Hence, the required nozzle section $A_{0}$ can be calculated from the formula:

$$
A_{0}=\frac{\pi \cdot D^{2}}{4}=\frac{p_{0} \cdot T}{T_{0} \cdot \Psi_{\max } \cdot \sqrt{\frac{R \cdot T}{\bar{M}}}}\left(\frac{\partial \dot{V}_{0}}{\partial p_{z}}\right)_{\beta<\beta_{k r}}
$$




\section{MEASUREMENTS}

The results of project assumptions required a validation in the course of the measurement process. For this purpose a system for the production of hydrogenair mixes was constructed, consisting of the following subsystems: measurement, air dosing, hydrogen dosing and a mixer.

a)

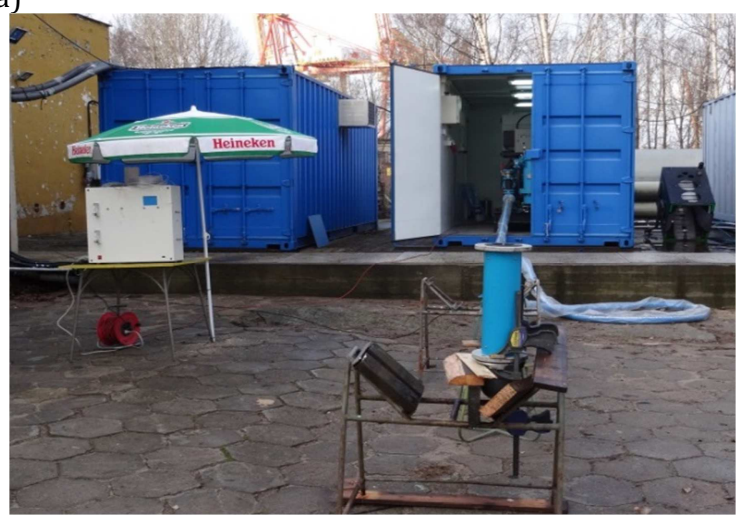

c)

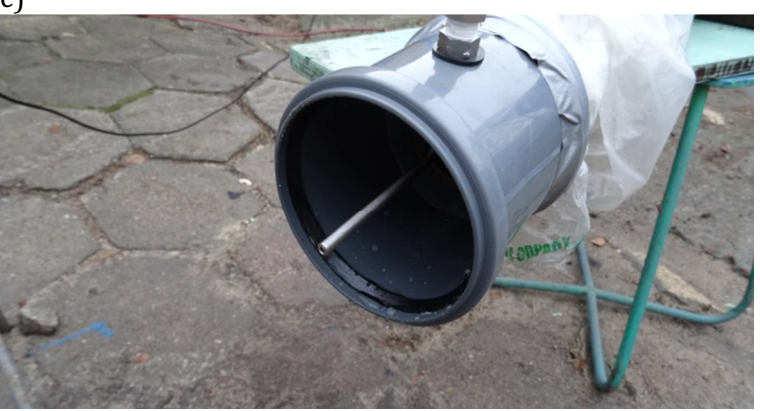

\section{AIR DOSAGE}

The tests related to the production of hydrogenair mixes were conducted with the use of a regeneration system displacement pump, controlled with an inverter, and ensuring a precise air flow so as to set the required stable levels - fig. $6 \mathrm{a}$. The system was linked via a flexible hose,with the head of a tubular reactor being connected to the hydrogen at a reduced pressure, a dosing nozzle and a tube supplying hydrogen in the axis

b)

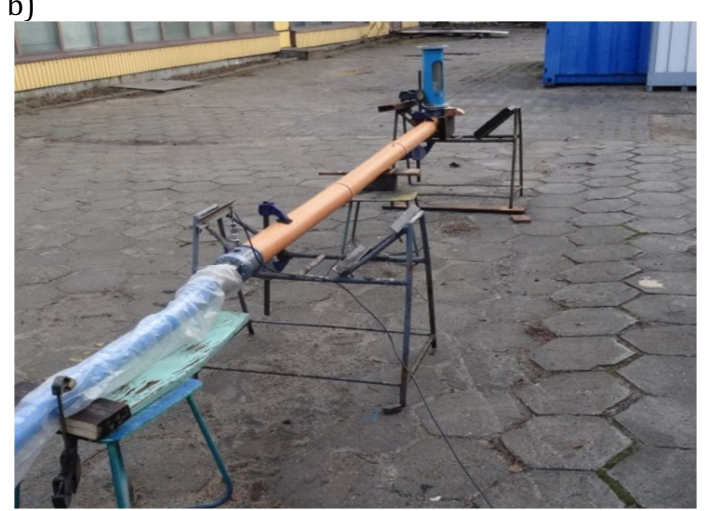

d)

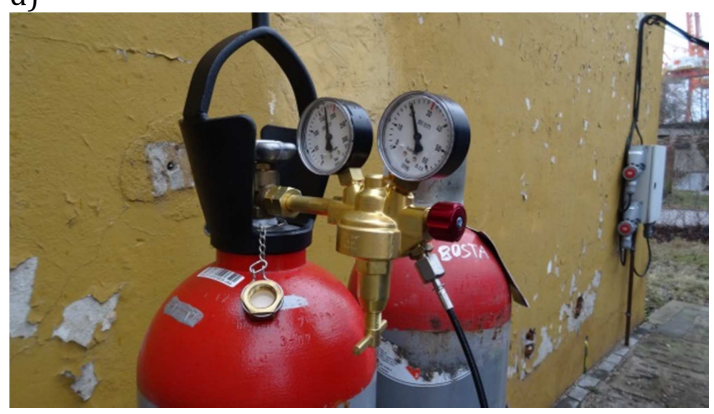

Fig. 9. A Tubular reactor for the production of a hydrogen-air mix: a) view of the air pump station located in the container, the rotametric measurement station is visible from the front; the station of hydrogen content measurement in the air is on the left; b) view of the pipe mixer; the connection of the pumping hose to the dosing head of the tubular reactor is visible closer to the reactor's inlet; c) view of the hydrogen line connection and hydrogen dosing tube to the tubular reactor; inside the hidden casing of the dosing nozzle; d) pressure regulator on the hydrogen supply

reactor - fig. 6c. The reduction of the pressure in the hydrogen line was performed via a pressure regulator fig. 6d. Before that the air flow was determined by utilising different settings of the inverter controlling the displacement pump supplying the air - tab. 3 .

\section{HYDROGEN DOSAGE}

The calculation of the section area $A_{0}$ of the nozzle responsible for dosing hydrogen, in relation to the temperature in which measurements were to be performed, was conducted on the basis of equation (24) and set at $t=0^{\circ} \mathrm{C}^{19}-\mathrm{tab}$. 4. Temperature determination allows for the quick design of the 
The air flow through the measurement station $\dot{V}_{0}$ related to normal conditions in inverter setting functions $F_{\%}$.

\begin{tabular}{|c|c|c|c|c|c|}
\hline $\begin{array}{c}\text { Inverter settings } \\
F_{\%} \\
\end{array}$ & $\begin{array}{c}\text { Air flow } \\
\dot{V}_{0} \\
\end{array}$ & $\begin{array}{c}\text { Inverter settings } \\
F_{\%}\end{array}$ & $\begin{array}{l}\text { Air flow } \\
\dot{V}_{0}\end{array}$ & $\begin{array}{c}\text { Inverter settings } \\
F_{\%}\end{array}$ & $\begin{array}{c}\text { Air flow } \\
\dot{V}_{0}\end{array}$ \\
\hline$[\mathrm{Hz} \%]$ & {$\left[m^{3} \cdot h^{-1}\right]$} & {$[\mathrm{Hz} \%]$} & {$\left[m^{3} \cdot h^{-1}\right]$} & {$[\mathrm{Hz} \%]$} & {$\left[m^{3} \cdot h^{-1}\right]$} \\
\hline 12,0 & 40 & 28,0 & 100 & 41,0 & 150 \\
\hline 14,5 & 50 & 30,5 & 110 & 44,0 & 160 \\
\hline 17,0 & 60 & 33,0 & 120 & 46,0 & 165 \\
\hline 19,5 & 70 & 35,5 & 130 & 47,5 & 170 \\
\hline 22,5 & 80 & 38,5 & 140 & 49,0 & 175 \\
\hline 25,5 & 90 & 40 & 145 & & \\
\hline
\end{tabular}

nozzles for the dosing system ${ }^{20}$ with the use of function relation (2 4). For this purpose, for hydrogen we may write: $\quad \frac{\dot{V}_{0}}{p_{z}} \cong 338.11 \cdot D^{2}$, where: $[D]=m m \quad$ and $\left[\frac{\dot{v}_{0}}{p_{z}}\right]=d m^{3} \cdot M P a^{-1} \cdot \min ^{-1}$.

While performing calculations for pressures above the critical pressure for hydrogen $p_{1}^{\text {min }} \gg 0.2 \mathrm{MPa}$ (22), it is possible to determine the diameter of the nozzle dosing hydrogen at $D \cong 0.3 \mathrm{~mm}$ - tab. 4 .
Rotametric measurements were carried out for the designed nozzle with the diameter of $d \cong 0.3 \mathrm{~mm}$ with regard to hydrogen flow $\dot{V}_{H_{2}}$. Measurements were carried out for indicative purposes to verify the correctness of the design of the hydrogen feeder, ignoring the differences concerning the conditions in which measurements are conducted and which were insignificantly different from normal conditions ${ }^{21}$. Results

Function $\left(\frac{\partial \dot{V}_{0}}{\partial p_{z}}\right)_{0^{\circ} \mathrm{C}}$ calculations for particular pure gases and mixtures.

\begin{tabular}{rlllllll}
\hline$p_{z}=$ & 0,200 & 0,247 & 0,500 & 1,000 & 1,500 & 2,462 & $\mathrm{MPa}$ \\
\hline$\dot{V}_{H_{2}}=$ & 6,06 & 7,50 & 15,16 & 30,43 & 45,67 & 75,00 & $\mathrm{dm}^{3} \cdot \mathrm{min}^{-1}$ \\
\hline$D=0,30$ & 0,30 & 0,30 & 0,30 & 0,30 & 0,30 & $\mathrm{~mm}$ \\
\hline
\end{tabular}

Function calculations $\left(\frac{\partial \dot{V}_{0}}{\partial p_{z}}\right)_{0^{\circ} \mathrm{C}}$ for particular pure gases and mixtures.

\begin{tabular}{|c|c|c|c|c|c|c|c|}
\hline$p_{z}=$ & 0,200 & 0,247 & 0,500 & 1,000 & 1,500 & 2,462 & $M P a$ \\
\hline$\dot{V}_{H_{2}}=$ & 6,06 & 7,50 & 15,16 & 30,43 & 45,67 & 75,00 & $d m^{3} \cdot \min ^{-1}$ \\
\hline$D=$ & 0,30 & 0,30 & 0,30 & 0,30 & 0,30 & 0,30 & $\mathrm{~mm}$ \\
\hline
\end{tabular}

calculations of the rotametric indications of the hydrogen dosage were performed according to relation (17) and collected in tab. 6. When comparing the results of theoretical calculations contained in tab. 5 and measurement results collected in tab. 6 we observe their satisfactory conformity.

\section{OBTAINING OF HYDROGEN-AIR MIXTURES}

The tests consisted in the sampling of the hydrogen-air mixture at three distances from the hydrogen dosing nozzle $l \in[0.91 ; 1.92 ; 2.91] m-$ fig. $7 \mathrm{~b}$. The averaged measurement results are shown in tab. 7.

The results of measurement of hydrogen dosage by nozzle $d \cong 0.3 \mathrm{~mm}$.

\begin{tabular}{|c|c|c|c|}
\hline $\begin{array}{c}\text { Feed } \\
\text { Pressure } \\
p_{z}\end{array}$ & $\begin{array}{c}\text { Rotameter indications } \\
\text { air scale } \\
\dot{V}_{0} \\
\end{array}$ & \multicolumn{2}{|c|}{$\begin{array}{l}\text { Calculations of rotameter indications } \\
\text { into hydrogen dosage } \dot{V}_{H_{2}}\end{array}$} \\
\hline$[\mathrm{MPa}]$ & {$\left[\mathrm{dm}^{3} \cdot \mathrm{h}^{-1}\right] \quad\left[\mathrm{dm}^{3} \cdot \mathrm{min}^{-1}\right]$} & {$\left[d m^{3} \cdot h^{-1}\right]$} & {$\left[\mathrm{dm}^{3} \cdot \min ^{-1}\right]$} \\
\hline 05 & 417 & 947 & 1580 \\
\hline 10 & 830 & 1.694 & 3144 \\
\hline 15 & 1180 & 2.689 & 4470 \\
\hline 20 & 1560 & 3.561 & 5909 \\
\hline 25 & 1.150 & 4.356 & 7258 \\
\hline \multicolumn{4}{|c|}{$\begin{array}{l}\text { Calculations of the indications were performed on the basis of equation } \dot{V}_{0}=\sqrt{\frac{p \cdot T_{0}}{p_{0} \cdot T}} \cdot \sqrt{\frac{\rho_{0}^{\prime}}{\rho_{0}}} \cdot \dot{V}_{H_{2}}, \\
\text { where: } \rho_{0}^{\prime} \text {-density of the liquid used in calibration in normal conditions; } \rho_{0} \text {-density of the measured liquid in normal } \\
\text { conditions, } \dot{V}_{0} \text {-volumetric flow rate of the measured mixture in relation to normal conditions }\left[T_{0}=273.15 \mathrm{~K} \wedge p_{0}=\right. \\
101.325 \mathrm{kPa}] ; T_{0} \text {-temperature in normal conditions }\left[T_{0}=273.15 \mathrm{~K}\right] ; p_{0} \text {-normal pressure }\left[p_{0}=101.325 \mathrm{kPa}\right] \\
p \text {-atmospheric pressure at the time of measurement; } \dot{V}_{\mathrm{H}_{2}} \text {-measured hydrogen flow in measurement conditions. }\end{array}$} \\
\hline
\end{tabular}


a)

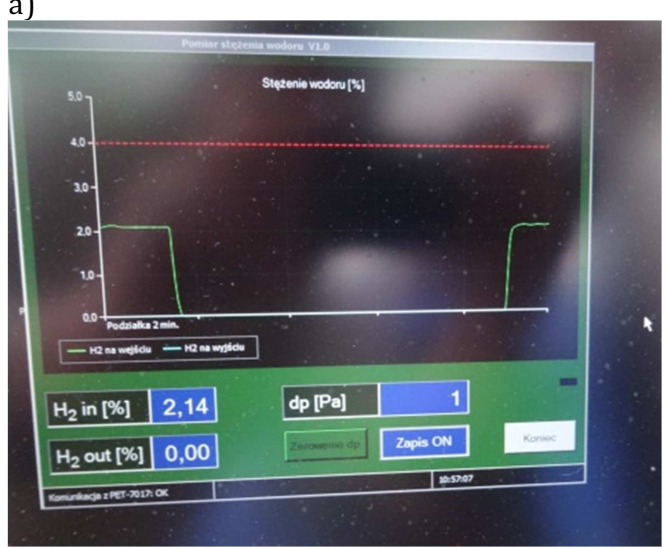

c)

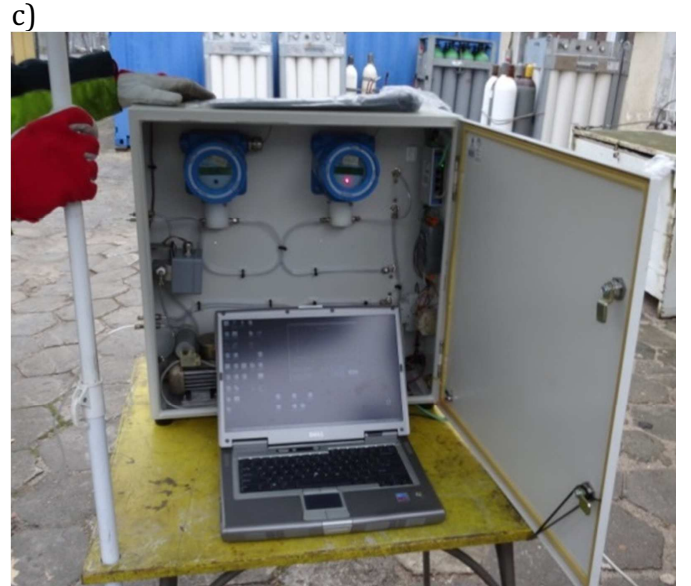

b)

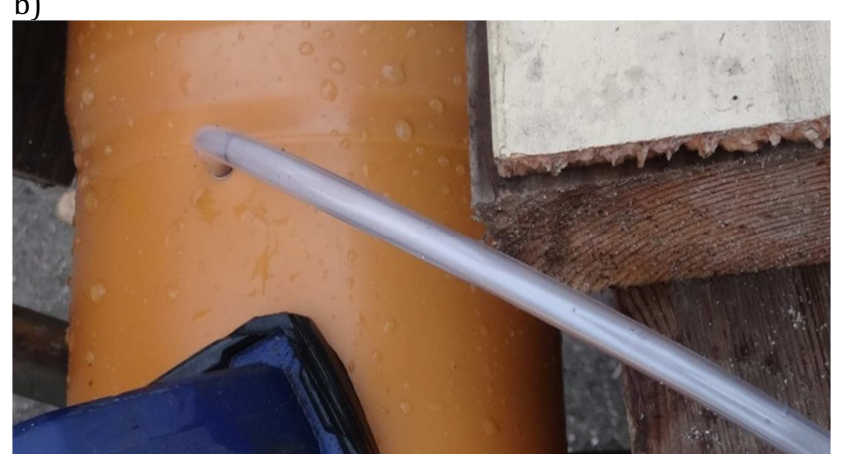

Fig. 10. The examination of the procedure of mixing hydrogen with air: a) measurement results presentation; b) sampling method; c) view of the measurement station

The system of obtaining the mix revealed a high repeatability and stability of the received composition of the hydrogen-air mix. Tests showed that already at the distance of ca. $1 \mathrm{~m}$ the mixture can be perceived as homogeneous. It had been decided to use a reactor with the length of approx. $2 \mathrm{~m}$.

The verification of conditions of production of hydrogen mixes in the air

\begin{tabular}{|c|c|c|c|c|c|}
\hline Inverter settings & Air stream & $\begin{array}{c}\text { Reduced } \\
\text { hydrogen } \\
\text { pressure }\end{array}$ & Hydrogen stream & Distance & $\begin{array}{c}\text { Measurement } \\
\text { hydrogen } \\
\text { concentrations }\end{array}$ \\
\hline$F_{\%}$ & $\dot{V}_{0}$ & $p_{H_{2}}$ & $\dot{V}_{H_{2}}$ & $l$ & $x_{\mathrm{H}_{2}}$ \\
\hline$[\mathrm{Hz} \%]$ & {$\left[m^{3} \cdot h^{-1}\right]$} & {$[M P a]$} & {$\left[m^{3} \cdot h^{-1}\right]$} & {$[m]$} & {$\left[m^{3} \cdot m^{-3}\right]$} \\
\hline 40 & 145 & 20 & 35 & 192 & 00211 \\
\hline 40 & 145 & 20 & 35 & 091 & 00213 \\
\hline 40 & 145 & 20 & 35 & 291 & 00214 \\
\hline
\end{tabular}

\section{Conclusions}

The measurement results presented in tab. 7 meet the quality requirements for the method of hydrogen-air mix production, for the purpose of conducting tests on the catalytic hydrogen combustion process. 


\title{
BIBLIOGRAPHY
}

1. Coward H.F., Jones G.W. 1952. Limits of flammability of gases and vapors. Washington : Bureau of Mines, 1952. Bulletin 503;

2. Shapiro Z.M., Moffette T.R. 1957. Hydrogen flamability data and application to PWR loss-of-cooiant accident. Pittsburgh : U.S. Atomic Energy Commission, 1957. WAPD-SC-545;

3. Das L.M. 1996. Hydrogen-oxygen reaction mechanism and its implication to hydrogen engine combustion. International Journal of Hydrogen Energy. 1996, Tom 21, 8, strony 703-715;

4. Krawczyk M. 2003. Flammability of gas mixtures. Chemical sensors in flammability measurements. [Lecture materials] Gdańsk: Politechnika Gdańska, 2003;

5. Morfin F., Sabroux J-C, Renouprez A. 2004. Catalytic combustion of hydrogen for mitigating hydrogen risk in case of a severe accident in a nuclear power plant: study of catalysts poisoning in a representative atmosphere. 2004, Tom 47, strony 47-58;

6. Goliński J.A., Troskalański A.T. 1979. Injectors. Warsaw : WNT, 1979;

7. Halupczok J. 1975. Subsonic gas injectors. Prace Naukowe Instytutu Inżynierii Chemicznej i Urządzeń Cieplnych. Wrocław: Politechnika Wrocławska, 1975

8. Gumiński K. 1974. Thermodynamics. Warsaw : PWN, 1974

9. Pigoń K., Ruziewicz Z. 2007. Physical Chemistry. Warsaw : Wydawnictwo Naukowe PWN, 2007. ISBN 978-83-01-15055-6;

10. Mittleman J. 1989. Computer modeling of underwater breathing systems. [red.] D.E.Warkander C.E.G.Lundgren. Physiological and human engineering aspects of underwater breathing apparatus. Bethesda : Undersea and Hyperbaric Medical Society, 1989;

11. Collective work. 1990. Metrology textbook. [ed.] P.H. Sydenham. Warsaw : Wydawnictwo Komunikacji i Łączności, 1990. Vol. I and II ISBN 83206-0681-0; ISBN 83-206-0812-0

\author{
dr hab. inż. Ryszard Kłos, prof. nadzw. AMW \\ Polish Naval Academy, \\ Department of Underwater Work Technology \\ 81 - 103 Gdynia 3 \\ ul. Śmidowicza 69 \\ Tel: +586262746, Fax: +586262761
}

\footnotetext{
${ }^{1}$ by definition Lower Explosive Limit is the lowest concentration of a flammable substance which allows sustenance of the combustion process after mixing it with an oxidant and triggering of ignition,

${ }^{2}$ by definition Upper Explosive Limit is the highest concentration of a flammable substance with a sufficient amount of an oxidant to sustain the combustion process after ignition is triggered

the range of dangerous concentrations of a flammable substance with an oxidant in which every mix is potentially hazardous,

${ }^{4}$ Explosive Range,

specified values LEL and UEL are not isothermal limits,

${ }^{6}$ the explosion proper consisting in a fast oxidation reaction which spreads at a lower speed than the speed of sound in this mix,

${ }^{7}$ an explosion generally spreading at a high hypersonic speed estimated in gases at $[1.8 ; 3] \mathrm{km} \cdot \mathrm{s}^{-1}$, causing an occurrence of a shockwave in the surrounding centre,

i.e. Pressurized Water Reactor

9 back pressure

${ }^{10}$ perfect gas

11 in thermodynamics, this function depends only on system condition, i.e. its current parameter values

${ }^{12}$ as opposed to, for instance, internal system energy,

${ }^{13} \mathrm{e}$.g. the size of volumetric work performed by the system is defined as an external pressure value and not the pressureof gas which performs work [8,9],

${ }^{14} \mathrm{du}=\mathrm{c}_{\mathrm{v}} \cdot \mathrm{dT}-\mathrm{p} \cdot \mathrm{dv} \mid \mathrm{du} \equiv 0$

${ }^{15}$ adiabatic equation $\mathrm{p} \cdot \mathrm{v}^{\mathrm{K}}=$ const

${ }^{16}$ an interesting relationship is revealed if we compare equations (8) and (6): $\int_{v_{1}}^{v_{2}} p \cdot d v=\kappa \cdot \int_{p_{1}}^{p_{2}} v \cdot d p$,

${ }^{17}$ for ideal gases, molar fraction is equal by number to volumetric fraction,

${ }^{18}$ relative error,

19 as it is not precisely known, and a different value from the one assumed here leads to minor error in the calculations,

${ }^{20}$ relation (Z4.28) from app.4 may constitute the basis for designing nozzles in reduction-dosage systems,

${ }^{21}$ measurements were performed in winter conditions at sea level.
} 